\title{
Resistance of wood from black pine (Pinus nigra var. austriaca) against weathering
}

\author{
Johannes Tintner ${ }^{1}$ (D) . Ena Smidt ${ }^{1}$
}

Received: 17 January 2018 / Accepted: 29 July 2018 / Published online: 21 August 2018

(c) The Author(s) 2018

\begin{abstract}
At present tapped wood of black pines (Pinus nigra var. austriaca) is mainly combusted. The priority of material use over thermal recycling has led to some considerations regarding the utilization of tapped wood. The high content of extractives suggests a higher natural durability, and therefore, the suitability for outdoor applications. Tapped and not tapped wood boards from black pine (sapwood and heartwood) were subjected to weathering tests to find out its resistance against abiotic stress. Additionally tapped wood particles with a high content of resin were exposed to weathering and to composting. Weathering caused roughness to increase. Infrared spectral characteristics revealed the differences before and after tapping and weathering. Principal component analyses supported the grouping according to the chemical changes. In heartwood the lignin band at $1510 \mathrm{~cm}^{-1}$ disappears and the typical resin band at $1688 \mathrm{~cm}^{-1}$ decreases considerably. The lignin band of resinous parts is affected neither by weathering nor by composting. However, the resin band shows an intensity decrease and broadening due to weathering and disappears during composting.
\end{abstract}

Keywords Pinus nigra $\cdot$ Weathering $\cdot$ FTIR spectroscopy

\section{Introduction}

Due to the high content of extractives Pinus nigra var. austriaca was tapped for resin in the past in some regions in Lower Austria. Resin from pines provided the raw material for chemicals such as turpentine and colophony that have served as precursor for diverse products such as mixtures of paints and colors, soap and pharmaceuticals since medieval times [1]. Gangemi [2] reports on the different interests in this raw material and on the effects of historical pitch production in Italy.

In the middle of the twentieth century natural resin was replaced by mineral oil-based chemicals. Therefore, the trade has been rigorously reduced in Europe. Since 2012 resin tapping has been part of the cultural heritage in Lower Austria, but only a few people exist who are proficient in

Johannes Tintner

johannes.tintner@boku.ac.at

Ena Smidt

ena.smidt@boku.ac.at

1 Department of Material Sciences and Process Engineering, University of Natural Resources and Life Sciences, Vienna, Peter Jordanstr. 82, 1190 Vienna, Austria this practice [3]. Today natural resin is used for some niche products, e.g., balms. Colophony from natural resin plays a role to improve the sound of string instruments [4].

The lesions caused by resin tapping lead to several physiological reactions of the tree. On the one hand, resin production is stimulated and on the other hand the tree tries to close the lesion by bark, which effects irregular growth and anomalous annual rings. Therefore, interest conflicts with wood production are inevitable. They are reported for Austria by Mazek-Fialla [5]. Gayer [6] described the negative impact on plant growth and wood quality. Thus, material utilization of the tapped trees is, therefore, limited and incineration has dominated. Up to now the processing of this material has focused on some special applications, e.g., wooden floors in theaters, fences of paddocks and handicraft.

Due to substantial stocks of Pinus nigra var. austriaca in Lower Austria, there are some considerations regarding the material utilization of tapped pine wood. Tapping causes the resin to fill the pores which results in a massive wood. Due to the high content of extractives tapped pine wood is thought to be resistant against weathering, and therefore, appropriate for outdoor applications. According to resource management and the priority of material recycling over thermal recycling there would be a potential for 
cascading of tapped wood. It was the objective of this study to test the timber of black pine regarding the behavior under abiotic and biotic conditions. The abiotic test focused on physical weathering including a sequence of UV radiation, temperature and humidity over a period of 12 weeks. The resulting effects were characterized by means of (FourierTransform Infrared Spectroscopy) FT-IR spectroscopy and roughness measurements. Furthermore, resinous wood was added to a composting process. Chemical changes were also revealed by means of spectral features and compared to abiotic effects.

\section{Materials and methods}

\section{Origin of the samples and sample preparation}

Black pines originated from the Piestingtal (Lower Austria, $47^{\circ} 55^{\prime} 10^{\prime \prime} \mathrm{N} 16^{\circ} 08^{\prime} 40^{\prime \prime} \mathrm{E}$ ) with a humid, temperate climate.

Five tapped and five not tapped black pines were available. Planed boards of $30 \times 8 \times 1 \mathrm{~cm}$ were produced from the stem section between 1 and $2 \mathrm{~m}$ height. They were used for the weathering tests. The boards were produced from sapwood and heartwood separately, additionally the parts strongly enriched in resin due to tapping (named "resinous" throughout the paper).

\section{Weathering}

Weathering tests were performed on a Q-Lab ® QUV/spray. Test parameters were set according to BS EN 927-6:2006 [7]. The cycle of one week is summarized in Table 1. This cycle was repeated 12 times ( $=12$ weeks).

\section{Composting}

Ten small particles $(2 \times 1 \times 0.3 \mathrm{~cm})$ of the resinous parts were subjected to an open composting process on the laboratory scale. They were added to the compost mixture containing fruits, vegetables, yard waste and bulk materials. The composting process took place during 3 and 6 months in a rotting box $(80 \times 40 \times 40 \mathrm{~cm})$ at room temperature with regular turning and moistening. The temperature within the windrow did not exceed $55{ }^{\circ} \mathrm{C}$. For FT-IR measurements of resinous particles compost residues were removed from the surface.

\section{FT-IR spectroscopy}

Infrared spectra were recorded at the surface of the boards before and after weathering and after co-composting of the resinous particles. Spectroscopic investigations were carried out with a Tensor 27 (Bruker $®$, Ettlingen) in the mid-infrared area $\left(4000-400 \mathrm{~cm}^{-1}\right)$ using the ATR mode. 64 scans were performed and corrected against air as background. The spectral resolution was $4 \mathrm{~cm}^{-1}$. Eight-ten spectra per board were recorded and vector normalized with the Bruker software OPUS $6.5^{\circledR}$ (Bruker, Ettlingen).

\section{Roughness}

The measurements were performed on a Taylor Hobson ${ }^{\circledR}$ Form-Talysurf $250 \mathrm{i}$.

\section{Statistical analysis}

Experimental data were set in a factorial design with the factors tapped/ not tapped, type of the board (sapwood, heartwood, or highly resinous parts due to tapping) and before/ after the accelerated weathering test. Principal Component Analysis (PCA) was calculated with the software Unscrambler X $10.1^{\circledR}$ (Camo, Oslo) to display the influencing factors [8]. Analysis of Variance (ANOVA) and Boxplots were performed with SPSS $21{ }^{\circledR}$ (IBM, Armonk). Additional FT-IR spectra of resinous samples before and after weathering and co-composting were subjected to a PCA.

\section{Results and discussion}

\section{Effect of accelerated weathering}

Two main processes are assumed to take place under the conditions of the accelerated weathering test. According to the literature changes in the resin content due to temperature and photodegradation of lignin due to UV radiation could be
Table 1 Settings of the weathering test of one cycle over one week

\begin{tabular}{|c|c|c|c|c|}
\hline Level & Function & Temperature & Duration & Conditions \\
\hline 1 & Condensation & $45( \pm 3)^{\circ} \mathrm{C}$ & $24 \mathrm{~h}$ & \\
\hline 2 & $\begin{array}{l}\text { Secondary cycle } \\
\text { level } 2 a+2 b\end{array}$ & & $\begin{array}{l}48 \text { cycles } 3 \mathrm{~h} \text { each, contain- } \\
\text { ing level } 2 a+2 b\end{array}$ & \\
\hline $2 a$ & UV & $60( \pm 3){ }^{\circ} \mathrm{C}$ & $2.5 \mathrm{~h}$ & $\begin{array}{c}0.89 \pm 0.1 \mathrm{~W} /\left(\mathrm{m}^{2}\right. \\
\mathrm{nm}) \text { at } 340 \mathrm{~nm}\end{array}$ \\
\hline $2 b$ & Sprinkling & & $0.5 \mathrm{~h}$ & 6-7 L/min, no UV \\
\hline
\end{tabular}


expected [9-12]. PCA were, therefore, based on the wavenumber range $1930-400 \mathrm{~cm}^{-1}$ where relevant bands contribute to sample segregation (Table 2).

The influence of tapping and weathering on sapwood and heartwood is shown in the Scores plots of the PCAs (Fig. 1a, b). The overlapping groups indicate that sapwood is not affected by tapping, whereas weathering causes chemical changes (Fig. 1a). They are explained with spectral characteristics in Fig. 2. Interpretation of PC can be done by the loadings (plots not shown). For sapwood the main bands relevant for the segregation are related to lignin $(1510,1260$ and $1217 \mathrm{~cm}^{-1}$ ) and the broad region with superimposed bands around $1050 \mathrm{~cm}^{-1}$. It demonstrates the major impact of weathering and the minimal effect of tapping on sapwood (seen in the scores of Fig. 1a). Heartwood and tapped heartwood are partly separated (Fig. 1b). According to the loadings plot of the first principal component (not shown) the band at $1688 \mathrm{~cm}^{-1}$ is responsible for the grouping. Segregation due to weathering takes place along the second principal component, where additionally also the lignin band of $1510 \mathrm{~cm}^{-1}$ is relevant. With regard to weathering there is no difference between tapped and not tapped sapwood and heartwood, respectively. Tapped and not tapped samples overlap. Resinous parts before and after weathering are segregated as well by the third principal component (Fig. 1c), where the typical resin bands at 1690 and $1276 \mathrm{~cm}^{-1}$ dominate the loadings.

The average spectra of resinous wood and heartwood of tapped pines before and after accelerated weathering indicate the responsible regions for sample segregation. They are displayed in Fig. 2. Weathering causes several changes. The concerned bands are listed in Table 2. The band at $1510 \mathrm{~cm}^{-1}$ (lignin) almost disappears, whereas the bands in the area from 1240 to $1030 \mathrm{~cm}^{-1}$ (cellulose) show a relative increase. The chemical process is paralleled by a noticeable change of color from brown to gray. The band at about $1688 \mathrm{~cm}^{-1}$ that can be assigned to the carbonyl stretch vibration of resin acids, features the most distinct change. The decrease of band intensity is weaker in resinous wood than in heartwood where the decrease of this band is paralleled by the relative increase of the $\mathrm{C}-\mathrm{O}-\mathrm{C}$ vibration (cellulose) at $1030 \mathrm{~cm}^{-1}$.

Changes of band (resin acid and lignin) intensities due to accelerated weathering are shown in Fig. 3. The boxplots reveal that the lignin band of resinous parts decreases to a comparable level with sapwood or heartwood. We focused on this specific band, as it is the most unmated band assigned to lignin. It has been used as the only band to predict lignin content [15]. All the other lignin bands are more or less superimposed by vibrations of other molecules. The resin content remains at a higher level, whereas in heartwood samples the resin band decreases strongly. The band at $1688 \mathrm{~cm}^{-1}$ has been assigned to the carbonyl-group specific for resin in resin channels [16].

For practical applications, the results indicate that the weathering of lignin on the surface is not changed anyhow by the resin content. For an outdoor application of such boards we might suggest a certain delay but no substantial prevention effect of weathering in terms of graying.

\section{Co-composting of highly resinous wood particles}

The composting process and accelerated weathering of resinous wood particles led to different chemical changes after 12 and 24 weeks, respectively, as revealed by spectral features. Figure 4 compares the spectral characteristics of resinous wood and resinous wood that was subjected to a composting process for 12 (resinous wood composted 12 weeks) and 24 weeks (resinous wood composted 24 weeks). Whereas the aromatic skeletal vibration of lignin at $1510 \mathrm{~cm}^{-1}$ decreases considerably due to weathering (see Fig. 2), the band is not affected by composting. Due to the composting process the main resin band at $1688 \mathrm{~cm}^{-1}$ shows a more conspicuous reduction. The lower intensity of this band is paralleled by
Table 2 Selected wavenumber range $1930-400 \mathrm{~cm}^{-1}$ for the PCAs in Fig. 1

\begin{tabular}{|c|c|c|c|}
\hline $\operatorname{Resin} \operatorname{acid}\left(\mathrm{cm}^{-1}\right)^{\mathrm{a}}$ & $\operatorname{Lignin}\left(\mathrm{cm}^{-1}\right)^{\mathrm{b}}$ & Cellulose $\left(\mathrm{cm}^{-1}\right)^{\mathrm{b}}$ & Band origin \\
\hline \multirow[t]{4}{*}{$1710-1688$} & & & Carbonyl- or carboxyl stretch \\
\hline & 1596 & & Aromatic skeletal \\
\hline & 1510 & & Aromatic skeletal \\
\hline & 1464 & & $\mathrm{CH}$-deformation \\
\hline 1453 & & & $\mathrm{CH}$-deformation \\
\hline \multirow[t]{4}{*}{1275} & & & $\mathrm{C}-\mathrm{O}$ stretch \\
\hline & 1269 & & $\mathrm{G}$ ring plus $\mathrm{C}=\mathrm{O}$ stretch \\
\hline & 1221 & & $\mathrm{C}-\mathrm{C}, \mathrm{C}-\mathrm{O}, \mathrm{C}=\mathrm{O}$ stretch \\
\hline & & $1240-1030$ & $\begin{array}{l}\mathrm{C}-\mathrm{H} \text { deformation, } \mathrm{C}-\mathrm{O} \\
\mathrm{C}-\mathrm{O}-\mathrm{C}\end{array}$ \\
\hline
\end{tabular}

${ }^{\mathrm{a}}$ Ters [13]

${ }^{\mathrm{b}}$ Schwanninger [14] 

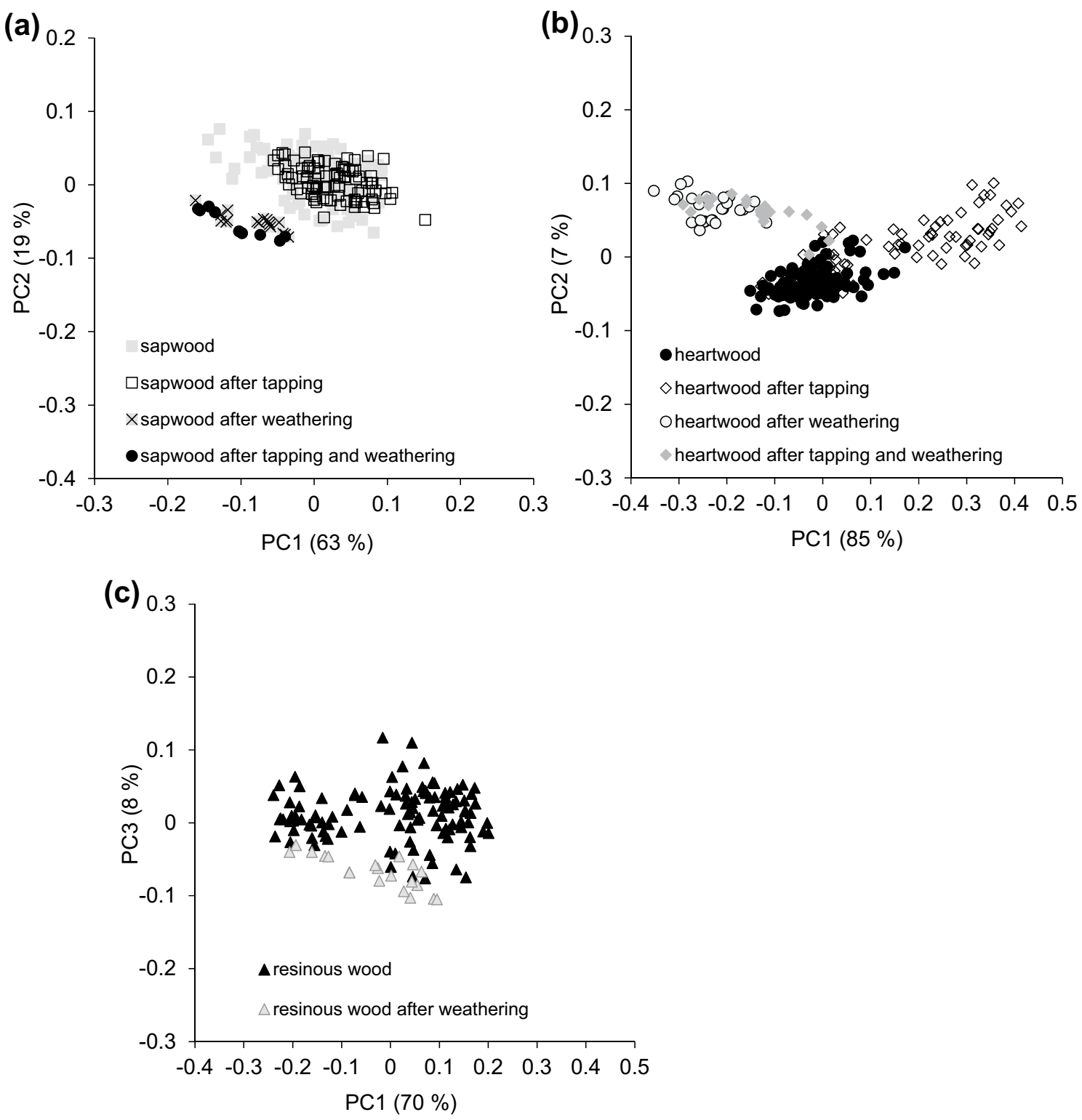

Fig. 1 Scores plots of the PCA based on infrared spectra of a sapwood and b heartwood, both after tapping, weathering and tapping plus weathering and of $\mathbf{c}$ resinous parts before and after weathering

the decrease of the bands at 2815 and $2865 \mathrm{~cm}^{-1}$ that are also assigned to resin acids, whereas the band at $3320 \mathrm{~cm}^{-1}$ (O-H vibrations) increase.

In the scores plot of the PCA (Fig. 5) resinous wood and composted resinous wood samples are located along the first principal component. The groups partly overlap. According to the loadings of the first principal component the bands at 2925, 2865 and $1688 \mathrm{~cm}^{-1}$ (resin acids), and the region $1240-1030 \mathrm{~cm}^{-1}$ (cellulose) contribute to sample segregation. Two samples that were composted for a longer time are located in a major distance. Weathered resinous wood samples are separated by the second principal component. Bands at 2925 and $2865 \mathrm{~cm}^{-1}$ and the region $1240-1030 \mathrm{~cm}^{-1}$ (cellulose) are also responsible for the grouping, but the strongest effect is caused by broadening and shifting of the band at $1688 \mathrm{~cm}^{-1}$.

The results obtained demonstrate the behavior of resinous wood in applications next to and beyond the soil surface. Composting can be seen as an accelerated test for these conditions. Even with the quite small experimental setup the results suggest that resin might protect the wood structure from microbial attack at least for a certain time till the resin itself is reduced. Further experiments could specify this effect. 


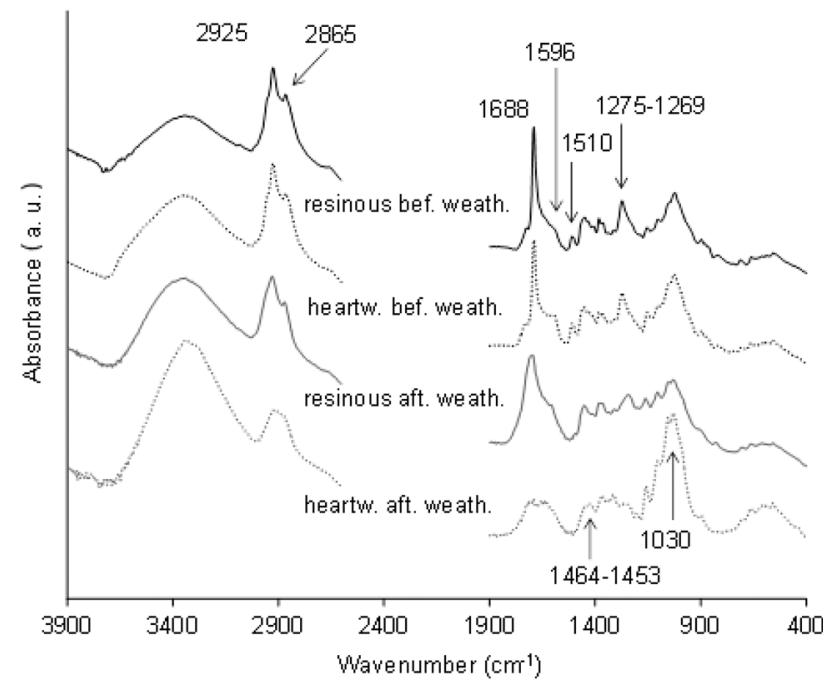

Fig. 2 Average FTIR spectra of the resinous part and of heartwood, both from tapped black pines, before and after accelerated weathering

\section{Roughness}

Figure 6 shows the effect of weathering on surface properties. The chemical change is paralleled by a relevant increase of roughness. Before weathering sapwood, heartwood and resinous parts of tapped wood feature similar results. Weathering leads to higher roughness. Sapwood is more affected than heartwood. Not tapped softwood and heartwood show higher roughness than the tapped sample. Nevertheless resinous parts are mostly affected by weathering.

\section{Conclusions}

The weathering test leads to a relevant decrease of resin and lignin contents in tapped black pine wood. Roughness and color of the surface are highly affected. The stability of tapped black pine wood in terms of outdoor utilization
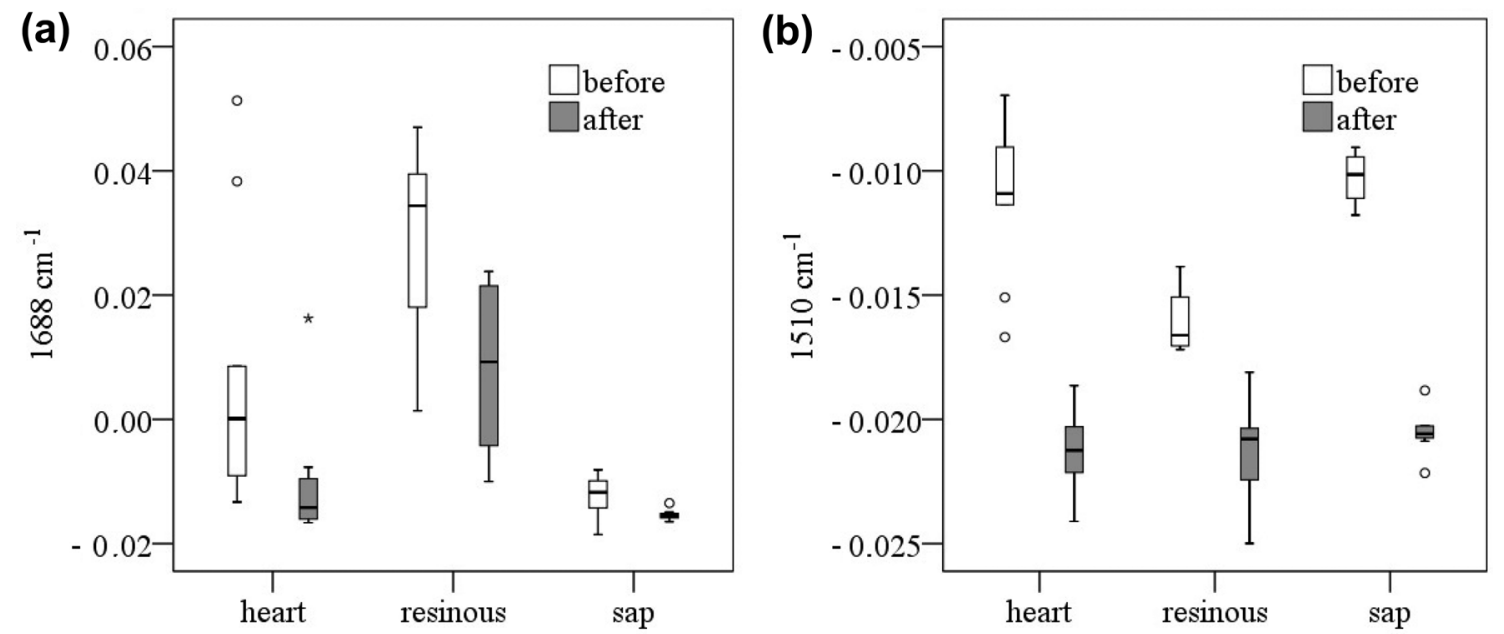

Fig. 3 Boxplots of FTIR band heights of a main resin band $\left(1688 \mathrm{~cm}^{-1}\right)$ and $\mathbf{b}$ of the main lignin band $\left(1510 \mathrm{~cm}^{-1}\right)$ before and after weathering

Fig. 4 Comparison of chemical changes due to composting revealed by spectral characteristics

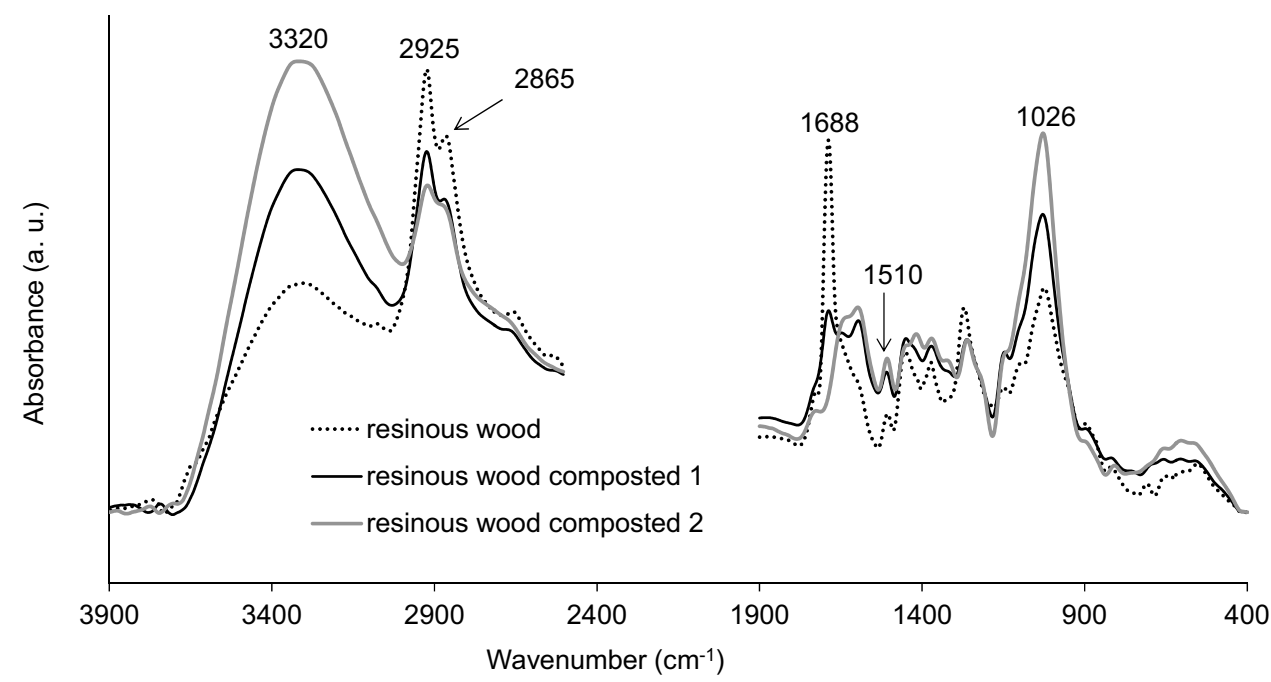




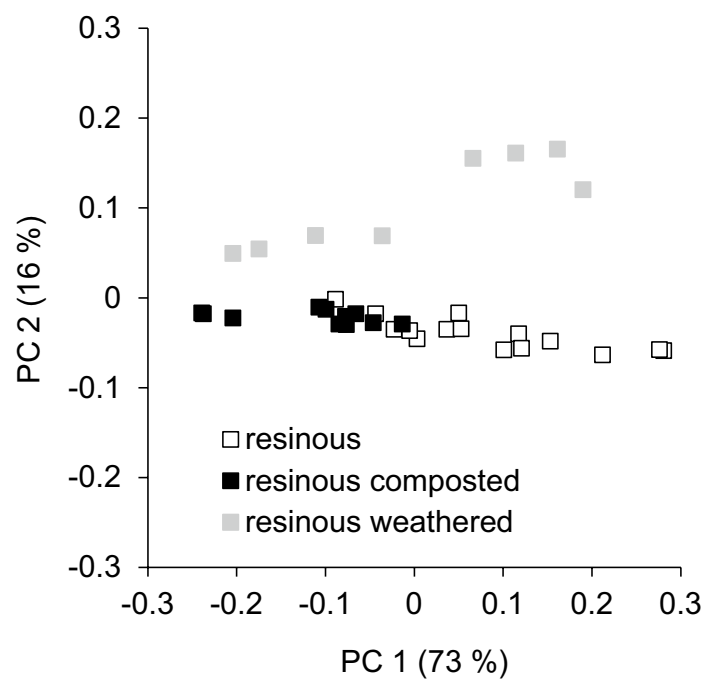

Fig. 5 Scores plot of the PCA based on infrared spectra (wavenumber range $3600-2700 \mathrm{~cm}^{-1}$ and $1780-900 \mathrm{~cm}^{-1}$ ) of resinous wood, resinous wood after accelerated weathering and after composting

rather focuses on the resistance against microbial attacks than on abiotic factors. According to the literature, abiotic weathering leads mainly to a destruction of lignin, whereas cellulose stays more stable. The main difference of tapping is the resin content, especially the highly resinous parts under the directly tapped part of the trunk. This resin featured more stable characteristics than lignin. Its characteristic band at $1688 \mathrm{~cm}^{-1}$ in the FTIR spectra was reduced after weathering, but at least at the highly resinous parts a certain amount remained. Despite higher roughness that can be explained by the decreasing lignin content, it can be concluded that the resin content protects wood against a subsequent biotic stress. The composting process affects more the resin acids, whereas the lignin $\left(1688 \mathrm{~cm}^{-1}\right)$ and cellulose $\left(1026 \mathrm{~cm}^{-1}\right)$ bands appear more distinct in the spectrum. It seems that a thin surface layer of resin protects lignin and cellulose. Further research of long-term composting experiments ( $>12$ months) will show, how wood components are affected after the destruction of the resin coating.
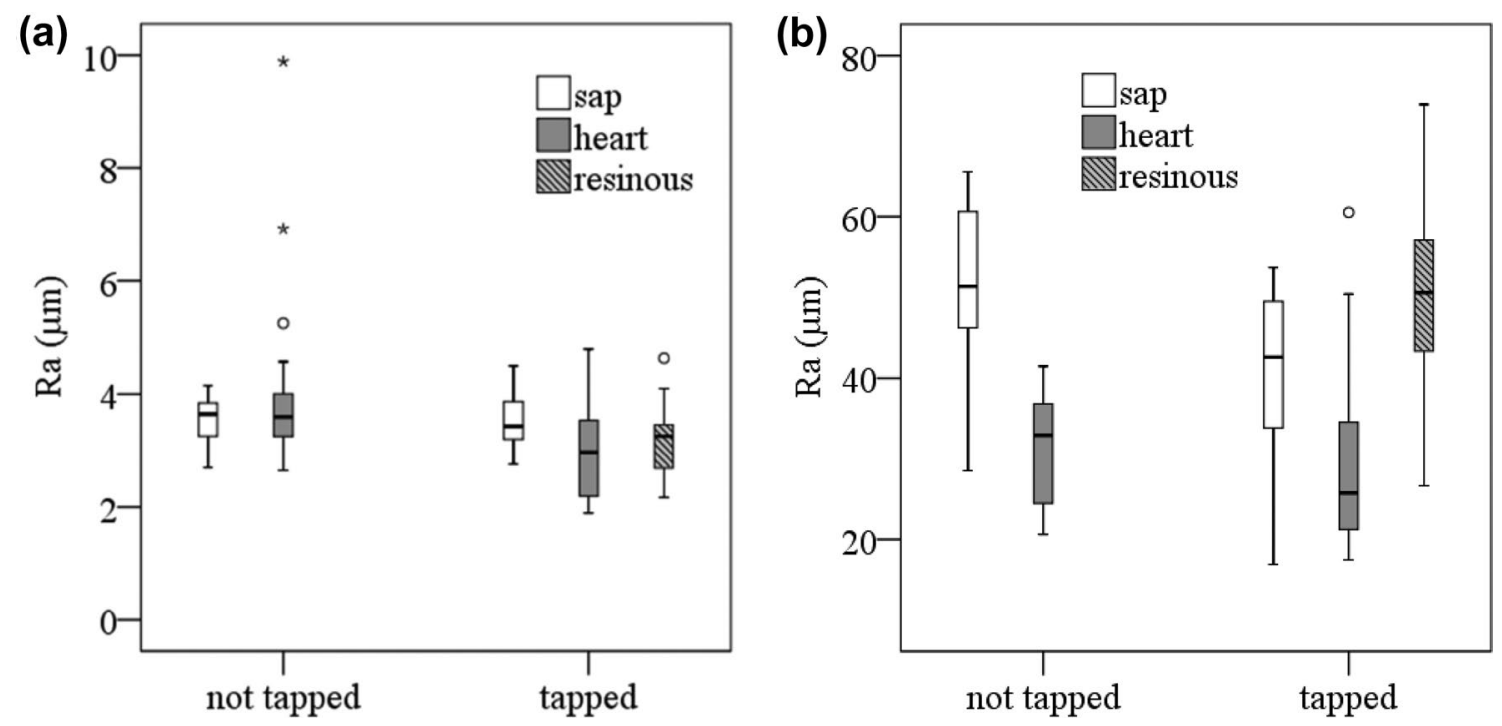

Fig. 6 Boxplots of roughness results $\mathbf{a}$ before and $\mathbf{b}$ after accelerated weathering test 
Acknowledgements Open access funding provided by University of Natural Resources and Life Sciences Vienna (BOKU). Many thanks to Gerhard Emsenhuber for the measurements of roughness and the accelerated weathering. Thanks to Herbert Kohlross, Michael Grabner and Czernin`sche Forstverwaltung for trees and sample preparation. The research was financed in the course of the Sparkling Science Project SPA 04-191.

\section{Compliance with ethical standards}

Conflict of interest The authors declare that there are no conflicts of interest.

Open Access This article is distributed under the terms of the Creative Commons Attribution 4.0 International License (http://creativeco mmons.org/licenses/by/4.0/), which permits unrestricted use, distribution, and reproduction in any medium, provided you give appropriate credit to the original author(s) and the source, provide a link to the Creative Commons license, and indicate if changes were made.

\section{References}

1. Grünn H (1960) Die Pecher. Manutius, Wien

2. Gangemi M (2007) Pitch production during the 18th century in Calabrian Sila (Italy). For Ecol Manage 249:39-44

3. http://www.unesco.at/kultur/immaterielles-kulturerbe/oesterreic hisches-verzeichnis/detail/article/pecherei-in-niederoesterreich/, Accessed 17 May 2018

4. Spinella A, Malagodi M, Saladino ML, Weththimuni ML, Caponetti E, Licchelli M (2017) A step forward in disclosing the secret of Stradivari's varnish by NMR spectroscopy. J Poly Sc Part A: Poly Chem 55:3949-3954

5. Mazek-Fialla K (1950) Die Holzbeschaffenheit nach der Harznutzung (in German). Wachek, Vienna
6. Gayer K (1888) Die Forstbenutzung (in German). Paul Parey, Berlin

7. European Standards (2006) Paints and varnishes. Coating materials and coating systems for exterior wood. Exposure of wood coatings to artificial weathering using fluorescent UV lamps and water, BS EN 927-6:2006

8. Esbensen K (2002) Multivariate Data Analysis-in practice. Alborg University, Esbjerg

9. Davidson RS (1996) The photodegradation of some naturally occurring polymers. J Photochem Photobio B: Biol 33:3-25

10. Sandak A, Sandak J, Riggio M (2016) Assessment of wood structural members degradation by means of infrared spectroscopy: An overview. Struct Contr Health Monit 23:396-408

11. Volkmer T, Noël M, Arnold M, Strautmann J (2016) Analysis of lignin degradation on wood surfaces to create a UV-protecting cellulose rich layer. Intern Wood Prod J 7:156-164

12. Žlahtič M, Humar M (2016) Influence of artificial and natural weathering on the hydrophobicity and surface properties of wood. BioResources 11:4964-4989

13. Ters T (2015) Messung von Extraktstoffen aus Kiefern und deren Abbau mittels biotechnologischer Methoden (in German). $\mathrm{PhD}$ Dissertation, University of Natural Resources and Life Sciences, Vienna

14. Schwanninger M (2007) Picea abies (L.) Karst. lignin determination in spruce wood with wet-lab-chemical and infrared spectroscopic methods using multivariate data analysis. PhD Dissertation, University of Natural Resources and Life Sciences, Vienna

15. Schwanninger M, Hinterstoisser B, Gradinger C, Messner K, Fackler K (2004) Examination of spruce wood biodegraded by Ceriporiopsis subvermispora using NIR and MIR spectroscopy. J Near Infrared Spectrosc 12(6):397-409

16. Holmgren A, Bergström B, Gref R, Ericsson A (1999) Detection of pinosylvins in solid wood of Scots pine using Fourier transform Raman and infrared spectroscopy. J Wood Chem Techn 19(1-2):139-150 